\title{
The Relationship of Smartphone Addiction and Alexithymia
}

\author{
İbrahim Gündoğmuş ${ }^{1}$, Mehmet Sinan Aydın², and Ayhan Algül ${ }^{3}$ \\ ${ }^{1}$ Department of Psychiatry, Kırıkkale Yüksek İhtisas Hospital, Kırıkkale, Turkey \\ ${ }^{2}$ Department of Psychiatry, Ortaca State Hospital, Muğla, Turkey \\ ${ }^{3}$ Department of Psychiatry, Sultan Abdulhamid Han Training and Research Hospital, Istanbul, Turkey
}

\begin{abstract}
Objective This study aims to evaluate whether smartphone addiction (SA) is associated with social media use and alexithymia levels in university students.

Methods A group of 935 students aged between 18 and 45 years (509 females and 426 males) was recruited from different universities in Istanbul. SAs, alexithymia and social media use were assessed using the Smartphone Addiction Scale Short Version (SAS-SV), Toronto Alexithymia Scale-20 (TAS-20), and ad-hoc questions regarding social media use.

Results The mean age of participants was $21.89 \pm 3.27$ years and 509 of participants were female (54.4\%). 455 (48.6\%) participants were placed in the "SA" and $198(21.2 \%)$ in the "alexithymia" categories. The study found a high level of positive correlation ( $<<0.001)$ between both subscale and total TAS-20 scores and SAS-SV scores. Gender (OR=1.496, 95\% CI 1.117-2.002, p=0.007) and number of social media by participants ( $O R=1.221,95 \%$ CI $1.134-1.315, \mathrm{p}<0.001)$ and TAS (OR=1.074, 95\% CI 1.059-1.090, $\mathrm{p}<0.001)$ were found to be an independent predictors for SA.
\end{abstract}

Conclusion The study revealed a positive correlation between alexithymia and smartphone use severity, and alexithymia was a significant predictor of SA. Future studies focusing on the causal aspect of this relationship will be useful in planning strategies for treatment.

Psychiatry Investig 2021;18(9):841-849

Keywords Addictions; Alexithymia; Content; Smartphone; Social media; User.

\section{INTRODUCTION}

Smartphones that include many features such as communications, games, videos, multimedia, access to the internet and social networks, messaging, and navigation are increasingly becoming indispensable in our daily life. ${ }^{1}$ The popularity of the smartphone and the deep connection of users with it have therefore raised concerns about its addictive potential. Notwithstanding the comfort it brings to our daily lives, one of the most important problems that we encounter with smartphones is "smartphone addiction (SA)", which is connected with a lack of control over smartphone usage. ${ }^{2}$ Although addiction is defined mostly through substance abuse, the APA defined gambling disorder as a non-substance-related addiction. ${ }^{3}$ This is an

Received: February 24, 2021 Revised: April 28, 2021

Accepted: July 1, 2021

$\triangle$ Correspondence: İbrahim Gündoğmuş, MD

Department of Psychiatry, Kırıkkale Yüksek İhtisas Hospital, Bağlarbaşı, Ahmet Ay Caddesi, 71300 Merkez/ Kırıkkale, Turkey Tel: +905455870575, E-mail: dribrahim06@gmail.com

(a) This is an Open Access article distributed under the terms of the Creative Commons Attribution Non-Commercial License (https://creativecommons.org/licenses/bync/4.0) which permits unrestricted non-commercial use, distribution, and reproduction in any medium, provided the original work is properly cited. important acquisition for behavioral addictions to be included in the literature, but SA is not yet included as a diagnosis in classifications such as DSM-5 and ICD-11. However, research on SA has increased significantly in recent years. ${ }^{4,5}$

The rapid development of smartphone technologies and having an Internet connection potentially anytime and everywhere are increasing concerns about SA. ${ }^{6}$ SA brings along physiological, psychological and social problems as in lots other addiction types. ${ }^{7}$ Decreasing performance in work or school, sleeplessness, relationship problems, withdrawal from social interactions in real life, dizziness, short-term memory problems, blurred vision, forgetfulness, and pain in the wrists or the back of the neck are just a few of these problems. ${ }^{8-14}$ In addition, SA has been associated with some mental health problems such as anxiety, depression and stress. ${ }^{15}$

Alexithymia, which is literally translated as "no words for mood," is a multifaceted personality construct that is defined as difficulty identifying and describing feelings, difficulty distinguishing feelings from bodily sensations, constricted imaginal processes with the inadequacy of fantasies, and a lack of concrete and poor introspective thinking. ${ }^{16}$ Furthermore, alexithymia has been defined as not only difficulty identifying sub- 
jective emotional states and a limited ability to communicate these feelings to others, but also a general impairment in emotional processing. ${ }^{17}$ Lumley and Roby ${ }^{17}$ suggested that individuals with high alexithymia, who also experience difficulties in emotional regulation, are in a relationship with some addictive behaviors to regulate their emotions. In addition, it has been observed that individuals who can distinguish, understand and regulate their emotions are more successful in managing addictive behaviors. ${ }^{18}$ An increasing body of evidence suggests that alexithymia can be present not only in substance addiction but also in several behavioral addictions. ${ }^{19}$ Among them, SA is particularly noteworthy. Individuals with alexithymia can use the internet to manage their problems in managing and defining emotions. ${ }^{20}$ Internet usage has become easier and more accessible with the rapid development of smartphones. ${ }^{21}$ Therefore, smartphone use and even addiction may be higher in individuals with alexithymia. Several previous studies investigating the relationship between alexithymia and SA were interesting. Alexithymia was positively associated with mental health problems and SA..$^{15,22-24}$ For example, previous studies have identified that alexithymia is associated with the severity of Internet addiction, problematic Internet use, and mobile phone use. ${ }^{15,25-27}$

Right at this point, this expected relation might have various reasons. It is already known that alexithymic individuals might experience emotional recognition difficulties causing more interpersonal problems. ${ }^{16}$ For this reason, using smartphones might increase the probability that these people escape and hide their true emotions. It might also increase the motivation to use smartphones to mitigate negative life situations and negative emotions. ${ }^{28}$ The individual might have a strong desire to spend more time with the smartphone, and this may result in addiction because the use of smartphones causes a distance from the problem in real life..$^{29}$ In other words, the individual might be using the smartphone as a strategy to cope with psychosocial problems. On the other hand, if it is difficult for alexithymic individuals to express their physical feelings and emotional state, it is probable that they will meet their psychological needs through a compensation mechanism. For this reason, they target to maintain the balance of their mental states. In such a situation, individuals tend to use smartphone excessively to achieve their goals, which can lead to a vicious cycle resulting in SA. ${ }^{30}$ There has been a limited number of studies investigating the relationship between alexithymia and SA. In addition to our knowledge, this issue has not been the subject of earlier research in Turkey.

Given all the existing evidence of smartphone use associated with alexithymia, it is possible that alexithymia is associated with SA. In the light of all this information, we hypothesized that: 1) students' alexithimia is associated with $S A ; 2$ ) alexithymia is a predictor of SA.

\section{METHODS}

\section{Participants}

This cross-sectional study was conducted in a random sample of 966 university students between March-September 2017. University students who applied to all the clinics and the health board of the Sultan Abdulhamid Han Training and Research Hospital, Turkey were included in the study regardless of their faculty of study. Informed consent was taken from all participants before filling out the questionnaires. Thirty-one students who refused to participate in the study or whose scales were filled incompletely were excluded from the study, and 935 students in total were included in the study. The criteria for inclusion in the study were: 1 ) still a student in university; 2) applied to the hospital where the study was conducted; 3) have no known mental illness; and 4) volunteered to participate in the study.

The study was carried out in accordance with the Declaration of Helsinki and approved by the local ethical committee of Haydarpasa Numune Training and Research Hospital, Turkey (IRB: 2018/174).

\section{Procedure}

Data were collected by a standard questionnaire including the Turkish version of the Smartphone Addiction Scale-Short Version (SAS-SV) ${ }^{31,32}$ and The Toronto Alexithymia Scale (TAS20). ${ }^{33-35}$ In addition, the participants were initially asked about some personal data, as well as social media use and further information about sociodemographic.

\section{The Smartphone Addiction Scale-Short Version (SAS-SV)}

The Turkish version of SAS-SV was used to evaluate smartphone use status. ${ }^{31}$ The SAS-SV is a 10-item, six-point Likerttype self-rating scale developed by Kwon. The Cronbach's alpha of the Turkish version of SAS-SV was found to be 0.94 . The options on the scale range from 1 to 6 (from "definitely not" to "absolutely yes"). The total score on the scale can range from 10 to 60 and as the score increases, the risk of SA increases. In the same way as Kwon et al., ${ }^{32}$ this study defined the SA group as $S A S-S V \geq 31$ for males and SAS-SV $\geq 33$ for females.

\section{The Toronto Alexithymia Scale (TAS-20)}

The Turkish version of the 20 -item TAS-20 was used as the measure of alexithymia. ${ }^{33}$ The options on the scale range from 1 to 5 (from "strongly disagree" to "strongly agree"). The total score on the scale can range from 20 to 100 , and as the score increases, the risk of alexithymia increases. TAS- 20 has a 3 -factor structure; the first factor is difficulty in identifying feelings (DIF) that consists of seven items, the second factor is difficulty in describing feelings (DDF) that consists of five items, and finally, the third factor is externally oriented thinking (EOT) 
consisting of eight items. Following Bagby et al., ${ }^{34}$ we defined the alexithymia group as TAS-20 $\geq 61$. The TAS-20 scale form was previously validated within the Turkish population. ${ }^{35}$

\section{Statistical analyses}

The data analysis was performed using the Statistical Package for Social Sciences (SPSS 20, IBM Corp., Armonk, NY, USA) software for Windows. Participants were assigned to SA group or non-SA group using the aforementioned definitions. Descriptive statistics were presented as mean \pm standard deviation and categorical variables were presented as frequency and percentages. The Student t test was used to compare two independent groups for cases with normally distributed variables and the One Way ANOVA test was used to compare more than two independent groups. Pearson correlations were used to determine the relationship between the variables. Finally, multivariate binary logistic regression analysis was performed to assess the influence of age, gender, place of residence, monthly income from family, number of social media, and TAS-20 score. The analysis was completed using the enter method, with SA group and non-SA group as dependent variables and age, gender, place of residence, monthly income from family, number of social media, and TAS-20 score as independent variables. The variables with a correlation coefficient higher than 0.7 were excluded to prevent collinearity in the logistic regression model. ORs the odds ratios (OR) and 95\% confidence intervals (CI) were calculated. Statistical significance was regarded to be $p$ values less than or equal to 0.05 .

\section{RESULTS}

The demographic data and prevalence rate of participating students are shown in Table 1 . The participants of our study were composed of 509 females (54.4\%), and 426 men (45.6\%). The mean age of participants was $21.89 \pm 3.27$ years. 455 (48.6\%) of the participants were placed in the "SA group" where SAS$\mathrm{SV} \geq 31$ for the males and SAS-SV $\geq 33$ for females. 198 (21.2\%) of the participants were placed in the "Alexithymia group" based on a TAS-20 score of $\geq 61$.

While the socio-demographic properties were compared, no significant difference was found in mean TAS-20 scores in terms of sex ( $\mathrm{p}=0.70)$, faculty of study $(\mathrm{p}=0.292)$, place of residence ( $\mathrm{p}=0.644)$, and monthly income received from family $(\mathrm{p}=0.296)$. A significant difference in mean TAS-20 score averages was found in terms of age $(\mathrm{p}=0.001)$, frequency of smartphone change $(\mathrm{p}<0.001)$, monthly smartphone bill $(\mathrm{p}=0.005)$ and SA $(p<0.001)$. A significant difference in mean SAS-SV scores was found in terms of sex $(p<0.001)$, age $(p=0.001)$, place of residence $(\mathrm{p}=0.008)$, monthly income received from family $(\mathrm{p}<0.001)$, frequency of smartphone change $(\mathrm{p}<0.001)$, and alexithymia $(\mathrm{p}<0.001)$ (Table 1$)$.

When the social media use and TAS scores were compared, a significant difference in mean TAS-20 scores was found in terms of Linkedln $(\mathrm{p}<0.001)$ and Shazam $(\mathrm{p}=0.017)$. A significant difference in mean SAS-SV scores were found in terms of Facebook $(p=0.001)$, Twitter $(p=0.001)$ Instagram $(p=0.001)$, Snapchat $(\mathrm{p}=0.001)$, Swarm $(\mathrm{p}=0.001)$ and Foursquare $(\mathrm{p}=$ 0.017 ) usage (Table 2).

The TAS-20 and subscale scores for each of the questions, "difficulty identifying feelings," "externally oriented thinking," and "difficulty expressing feelings," were statistically significantly higher among individuals with SA than others $(\mathrm{p}<0.001)$ (Table 3).

A high level of positive correlation $(\mathrm{p}<0.001)$ between both subscale and total TAS-20 scores and SAS-SV scores (Table 4 and Figure 1) was found. The predictors of SA were evaluated with the logistic regression analysis in Table 5. According to the logistic regression model where age, gender, place of residence, monthly income, number of social media and TAS are considered together $\left(\chi^{2}=153 ; \mathrm{df}=9 ; \mathrm{p}<0.001\right)$, gender $(\mathrm{OR}=$ $1.496,95 \%$ CI 1.117-2.002, $\mathrm{p}=0.007)$ and number of social me$\mathrm{dia}(\mathrm{OR}=1.221,95 \% \mathrm{CI} 1.134-1.315, \mathrm{p}<0.001)$ and TAS $(\mathrm{OR}=$ $1.074,95 \%$ CI $1.059-1.090, \mathrm{p}<0.001)$ were found to be a significant predictor of SA.

\section{DISCUSSION}

According to the results of the present study, which investigated the relation between alexithymia, SA, and social media use, there was a positive relationship between alexithymia and smartphone use severity, and alexithymia was a significant predictor of SA. However, generally there no relationship between social media use and alexithymia was found. On the other hand, our results have showed that social media use increases the risk of SA.

The main findings are that the alexithymia scores were higher among the SA group than in non-SA group, and alexithymia was an independent predictor of SA. In addition, not only total alexithymia scores but also subscale scores were statistically significantly correlated with SA. These findings are compatible with the recent studies which reported that smartphone use is associated with alexithymia. ${ }^{15,21,23-25}$ In the light of the literature, probable conceptual explanations may be suggested for the relationship between alexithymia and SA. It is known that alexithymia is a stable personality trait that includes low self-esteem, difficulty in establishing healthy and sincere social relationships, a tendency to externalize feelings and experiences, inability to correctly identify and manage emotional states, as well as a diminished ability to identify and explain emotions. ${ }^{19,36,37}$ From this perspective, a few ideas that may explain this relationship 
Table 1. Characteristics of the participants, comparisons of mean values for TAS-20 and SAS-SV in different groups

\begin{tabular}{|c|c|c|c|c|c|c|c|}
\hline \multirow{2}{*}{ Variable } & \multirow{2}{*}{$\mathrm{N}(\%)$} & \multicolumn{3}{|c|}{ TAS-20 total score } & \multicolumn{3}{|c|}{ SAS-SV score } \\
\hline & & Mean & $\mathrm{SD}$ & $\mathrm{p}$ & Mean & SD & $\mathrm{p}$ \\
\hline All participants & 935 & 51.83 & 11.06 & & 32.21 & 11.35 & \\
\hline Sex & & & & $0.70^{\dagger}$ & & & $<0.001^{* \dagger}$ \\
\hline Female & $509(54.4)$ & 51.23 & 10.97 & & 34.08 & 11.23 & \\
\hline Male & $426(45.6)$ & 52.55 & 11.14 & & 29.94 & 11.09 & \\
\hline Age (yr) & & & & $0.001^{* \ddagger}$ & & & $0.002^{* \ddagger}$ \\
\hline $18-21$ & $486(52)$ & 52.65 & 11.55 & & 33.55 & 11.21 & \\
\hline $22-25$ & $366(39.1)$ & 51.72 & 11.72 & & 30.88 & 11.25 & \\
\hline $26-29$ & $54(5.8)$ & 48.38 & 10.26 & & 30.59 & 12.29 & \\
\hline$\geq 30$ & $29(3.1)$ & 45.93 & 9.60 & & 29.48 & 10.78 & \\
\hline Faculty & & & & $0.292^{\ddagger}$ & & & $0.141^{\ddagger}$ \\
\hline Medicine & $88(9.4)$ & 52.31 & 10.07 & & 32.27 & 10.60 & \\
\hline Law & $58(6.2)$ & 49.36 & 10.92 & & 33.58 & 11.28 & \\
\hline Education & $114(12.2)$ & 50.82 & 10.84 & & 32.39 & 11.53 & \\
\hline Economics & $119(12.7)$ & 52.51 & 12.38 & & 33.57 & 12.56 & \\
\hline Engineering & $288(30.8)$ & 51.69 & 10.91 & & 30.63 & 10.97 & \\
\hline Healthy sciences & $141(15.1)$ & 51.39 & 10.64 & & 32.02 & 11.04 & \\
\hline Junior technical college & $67(7.2)$ & 53.52 & 10.71 & & 34.00 & 11.14 & \\
\hline Other & $60(6.4)$ & 53.95 & 12.15 & & 33.73 & 11.97 & \\
\hline Place of residence & & & & $0.427^{\ddagger}$ & & & $0.008^{* \ddagger}$ \\
\hline Family & $375(40.1)$ & 50.66 & 11.21 & & 31.99 & 11.19 & \\
\hline Friend & $209(22.4)$ & 53.89 & 11.23 & & 32.44 & 11.76 & \\
\hline Alone & $81(8.7)$ & 51.14 & 11.09 & & 32.19 & 11.27 & \\
\hline Student hostel & $27(28.9)$ & 52.07 & 10.52 & & 33.11 & 11.28 & \\
\hline Monthly income from family & & & & $0.296^{\ddagger}$ & & & $<0.001^{* \ddagger}$ \\
\hline Low & $227(24.3)$ & 53.08 & 10.55 & & 31.74 & 11.94 & \\
\hline Middle & $417(44.6)$ & 52.76 & 10.96 & & 32.85 & 11.13 & \\
\hline High & $291(31.1)$ & 49.52 & 11.28 & & 31.64 & 11.18 & \\
\hline Frequency of smartphone change (yr) & & & & $<0.001^{* \ddagger}$ & & & $<0.001^{* \ddagger}$ \\
\hline $0-1$ & $26(2.8)$ & 58.92 & 10.47 & & 37.19 & 12.14 & \\
\hline $1-2$ & $195(20.9)$ & 55.00 & 12.09 & & 35.46 & 11.97 & \\
\hline $2-4$ & $506(54.1)$ & 51.32 & 10.61 & & 32.49 & 11.04 & \\
\hline$\geq 4$ & $208(22.2)$ & 49.24 & 10.21 & & 27.86 & 9.97 & \\
\hline Monthly smartphone bill & & & & $0.005^{* \ddagger}$ & & & $0.054^{\ddagger}$ \\
\hline Very low & $104(11.1)$ & 52.34 & 10.74 & & 31.18 & 11.75 & \\
\hline Low & $535(57.2)$ & 52.31 & 10.95 & & 31.77 & 11.19 & \\
\hline Middle & $192(20.5)$ & 52.21 & 11.32 & & 32.52 & 11.17 & \\
\hline High & $104(11.1)$ & 48.15 & 10.92 & & 34.90 & 11.83 & \\
\hline Smartphone addiction & & & & $<0.001^{* \dagger}$ & & & $<0.001^{* \dagger}$ \\
\hline Yes & $455(48.7)$ & 55.50 & 10.87 & & 41.79 & 7.23 & \\
\hline No & $480(51.3)$ & 48.36 & 10.09 & & 23.13 & 5.64 & \\
\hline TAS-20 & & & & $<0.001^{* \dagger}$ & & & $<0.001^{* \dagger}$ \\
\hline Alexithymic & $198(21.2)$ & 67.46 & 5.42 & & 38.67 & 11.72 & \\
\hline Non-alexithymic & $737(78.8)$ & 47.63 & 8.01 & & 30.47 & 10.60 & \\
\hline
\end{tabular}


Table 2. Characteristics of social media use of participants, comparisons of mean values for TAS-20 and SAS-SV in social media

\begin{tabular}{|c|c|c|c|c|c|c|c|}
\hline \multirow{2}{*}{ Variable } & \multirow{2}{*}{$\mathrm{N}(\%)$} & \multicolumn{3}{|c|}{ TAS-20 total score } & \multicolumn{3}{|c|}{ SAS-SV score } \\
\hline & & Mean & $\mathrm{SD}$ & $\mathrm{p}$ & Mean & $\mathrm{SD}$ & $\mathrm{p}$ \\
\hline Type of social media & & & & $0.630^{\dagger}$ & & & $0.008^{* \dagger}$ \\
\hline There is social media use & $901(96.4)$ & 51.80 & 11.06 & & 32.40 & 11.33 & \\
\hline None & $34(3.6)$ & 52.73 & 11.28 & & 27.14 & 10.70 & \\
\hline Facebook & & & & $0.581^{\dagger}$ & & & $0.001^{* \dagger}$ \\
\hline Yes & $729(78)$ & 51.94 & 11.16 & & 32.80 & 11.54 & \\
\hline No & $206(22)$ & 51.46 & 10.74 & & 30.11 & 10.39 & \\
\hline Twitter & & & & $0.446^{\dagger}$ & & & $<0.001^{* \dagger}$ \\
\hline Yes & $503(53.8)$ & 52.09 & 11.51 & & 34.61 & 10.77 & \\
\hline No & $432(46.2)$ & 51.53 & 10.52 & & 29.41 & 10.16 & \\
\hline Instagram & & & & $0.446^{\dagger}$ & & & $<0.001^{*+}$ \\
\hline Yes & $763(81.6)$ & 51.86 & 10.97 & & 33.31 & 11.22 & \\
\hline No & $172(18.4)$ & 51.72 & 11.52 & & 27.30 & 10.62 & \\
\hline Snapchat & & & & $0.341^{\dagger}$ & & & $<0.001^{* \dagger}$ \\
\hline Yes & $528(56.5)$ & 52.14 & 11.33 & & 34.14 & 11.36 & \\
\hline No & $407(43.5)$ & 51.44 & 10.70 & & 29.70 & 10.84 & \\
\hline Linkedln & & & & $<0.001^{*+}$ & & & $0.236^{\dagger}$ \\
\hline Yes & $144(15.4)$ & 48.51 & 11.65 & & 31.18 & 11.56 & \\
\hline No & 791 (84.6) & 52.44 & 10.85 & & 32.39 & 11.31 & \\
\hline Swarm & & & & $0.933^{\dagger}$ & & & $<0.001^{* \dagger}$ \\
\hline Yes & $323(34.5)$ & 51.92 & 11.54 & & 35.41 & 11.37 & \\
\hline No & $612(65.5)$ & 51.79 & 10.81 & & 30.51 & 10.97 & \\
\hline Shazam & & & & $0.017^{* \dagger}$ & & & $0.559^{\dagger}$ \\
\hline Yes & $176(18.8)$ & 50.03 & 11.26 & & 31.76 & 11.06 & \\
\hline No & $759(81.2)$ & 52.25 & 10.98 & & 32.31 & 11.42 & \\
\hline Pinterest & & & & $0.065^{\dagger}$ & & & $0.997^{\dagger}$ \\
\hline Yes & $102(10.9)$ & 49.93 & 10.67 & & 32.21 & 10.05 & \\
\hline No & $803(89.1)$ & 52.07 & 11.09 & & 32.21 & 11.50 & \\
\hline Foursquare & & & & $0.120^{\dagger}$ & & & $<0.001^{* \dagger}$ \\
\hline Yes & $118(12.6)$ & 50.35 & 10.07 & & 35.84 & 11.73 & \\
\hline No & $817(87.4)$ & 52.05 & 11.19 & & 31.68 & 11.20 & \\
\hline
\end{tabular}

${ }^{*} \mathrm{p}<0.05$; ${ }^{\dagger}$ student-t test. TAS-20, 20-Item Toronto Alexithymia Scale; SAS-SV, Smartphone Addictions Scale Short Version; SD, standard deviation

Table 3. Comparison of alexithymia total and subscale scores based on students with and without SA

\begin{tabular}{|c|c|c|c|c|}
\hline & SA & Non-SA & \multirow{2}{*}{$\mathrm{t}$ value $(\mathrm{df})$} & \multirow{2}{*}{$\mathrm{p}$ value } \\
\hline & Mean \pm SD & Mean \pm SD & & \\
\hline Total TAS-20 score & $55.50 \pm 10.87$ & $48.36 \pm 10.09$ & $10.41(933)$ & $<0.001^{*}$ \\
\hline Difficulties identifying feelings score & $19.74 \pm 6.21$ & $15.69 \pm 5.31$ & $10.69(933)$ & $<0.001^{*}$ \\
\hline Difficulties describing feelings score & $13.99 \pm 4.09$ & $12.11 \pm 3.85$ & $7.24(933)$ & $<0.001^{*}$ \\
\hline Externally oriented thinking Score & $21.75 \pm 3.69$ & $20.55 \pm 3.60$ & $5.04(933)$ & $<0.001^{*}$ \\
\hline
\end{tabular}

${ }^{*} \mathrm{p}<0.05$. Difficulties İdentifying Feelings is TAS-20 subscale; Difficulties Describing Feelings is TAS-20 subscale; Externally Oriented Thinking is TAS-20 subscale. SA, smartphone addiction; TAS-20, 20-Item Toronto Alexithymia Scale; SD, standard deviation 
Table 4. Correlations between scale scores

\begin{tabular}{|c|c|c|c|c|c|c|}
\hline & 1 & 2 & 3 & 4 & 5 & 6 \\
\hline 1- TAS-20 total score & 1 & & & & & \\
\hline \multicolumn{7}{|l|}{ 2- DDF score } \\
\hline $\mathrm{r}$ & $0.895^{* *}$ & 1 & & & & \\
\hline $\mathrm{p}$ & $<0.001$ & & & & & \\
\hline \multicolumn{7}{|l|}{ 3- DIF score } \\
\hline $\mathrm{r}$ & $0.878^{* *}$ & $0.754^{* *}$ & 1 & & & \\
\hline $\mathrm{p}$ & $<0.001$ & $<0.001$ & & & & \\
\hline \multicolumn{7}{|l|}{ 4- EOT score } \\
\hline $\mathrm{r}$ & $0.544^{* *}$ & $0.193^{* *}$ & $0.278^{* *}$ & 1 & & \\
\hline $\mathrm{p}$ & $<0.001$ & $<0.001$ & $<0.001$ & & & \\
\hline \multicolumn{7}{|l|}{ 5- SAS-SV score } \\
\hline $\mathrm{r}$ & $0.403^{* *}$ & $0.413^{* *}$ & $0.293^{* *}$ & $0.201^{* *}$ & 1 & \\
\hline $\mathrm{p}$ & $<0.001$ & $<0.001$ & $<0.001$ & $<0.001$ & & \\
\hline \multicolumn{7}{|c|}{ 6- Number of social media } \\
\hline $\mathrm{r}$ & -0.036 & -0.007 & -0.043 & -0.049 & $0.224^{* *}$ & 1 \\
\hline $\mathrm{p}$ & 0.268 & 0.832 & 0.186 & 0.131 & $<0.001$ & \\
\hline \multicolumn{7}{|l|}{ 7- Age } \\
\hline $\mathrm{r}$ & $-0.126^{* *}$ & $-0.148^{* *}$ & $-0.102^{* *}$ & -0.019 & $-0.119^{* *}$ & -0.002 \\
\hline $\mathrm{p}$ & $<0.001$ & $<0.001$ & 0.002 & 0.569 & $<0.001$ & 0.946 \\
\hline
\end{tabular}

${ }^{* *} \mathrm{p}<0.001$. TAS-20, 20-Item Toronto Alexithymia Scale; SAS-SV, Smartphone Addictions Scale Short Version; DIF, TAS-20 factor for difficulties identifying feelings; DDF, TAS-20 factor for difficulties describing feelings; EOT, TAS-20 factor for externally oriented thinking

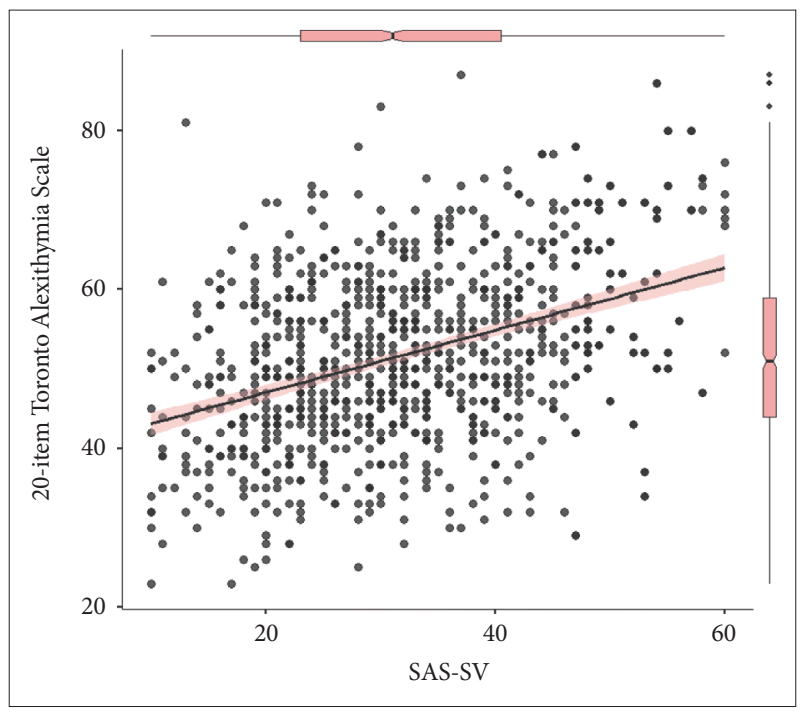

Figure 1. The graphical representation of the correlation between the SAS-SV and TAS-20 scores. SAS-SV, Smartphone Addictions Scale Short Version; TAS-20, 20-Item Toronto Alexithymia Scale.

can be raised. The most possible reason can be that a person with high levels of alexithymia develops addictive behavior as a way to regulate their affective states and to feel more comfortable through online social interactions. ${ }^{20}$ Furthermore, a person with high levels of alexithymia with an undesirable con- dition, such as low self-esteem, physical inadequacy or a lack of social support may use smartphones to relieve these emotions externally as a defense mechanism, and it may also be an escape from feelings that would be emotionally painful. ${ }^{26,38} \mathrm{In}$ dividuals with high levels of alexithymia have difficulty in accurately defining and managing emotional situations and this creates problems in initiating and maintaining social relationships. ${ }^{39}$ This problem may cause more use of smartphones because they facilitate interpersonal relationships for individuals with alexithymia. ${ }^{40,41}$

In the literature, there are studies showing that social media networks, which are one of the greatest conveniences of using smartphones, can increase SA. ${ }^{7,42,43}$ The present study showed that social media use increases the risk of $\mathrm{SA}$ in accordance with the literature. ${ }^{44}$ The results showed that students using Facebook, Twitter, Instagram, Snapchat, Swarm, and Foursquare are at greater risk of addiction than students who do not use them. In contrast to this, LinkedIn, Shazam and Pinterest were not found to increase the risk of SA. It is very difficult to interpret and analyze these findings because the social networks evaluated are very different from each other. ${ }^{44}$ However, the results of the current study provide some explanations. Generally, when social networks that increase the risk of addiction are examined, some of their features are noteworthy. ${ }^{45,46}$ Re- 
| Gündoğmuş et al.

Table 5. Logistic regression model created to determine predictors of smartphone addiction

\begin{tabular}{|c|c|c|c|c|c|c|c|c|}
\hline \multirow{2}{*}{ Predictors } & \multirow{2}{*}{ B } & \multirow{2}{*}{ S.E. } & \multirow{2}{*}{ Wald } & \multirow{2}{*}{$\mathrm{df}$} & \multirow{2}{*}{$\mathrm{p}$} & \multirow{2}{*}{$\begin{array}{c}\text { Odds } \\
\text { ratio }\end{array}$} & \multicolumn{2}{|c|}{$95 \% \mathrm{CI}$} \\
\hline & & & & & & & Lower & Upper \\
\hline Age (1-point increase) & -0.023 & 0.024 & 0.969 & 1 & 0.325 & 0.977 & 0.933 & 1.023 \\
\hline Gender (female) & 0.403 & 0.149 & 7.316 & 1 & 0.007 & 1.496 & 1.117 & 2.002 \\
\hline \multicolumn{9}{|l|}{ Place of residence } \\
\hline Family & & & 3.757 & 3 & 0.289 & 1 & & \\
\hline Friend & -0.274 & 0.197 & 1.939 & 1 & 0.164 & 0.760 & 0.516 & 1.118 \\
\hline Alone & -0.016 & 0.275 & 0.003 & 1 & 0.954 & 0.984 & 0.574 & 1.687 \\
\hline Student hostel & 0.124 & 0.177 & 0.493 & 1 & 0.482 & 1.132 & 0.801 & 1.602 \\
\hline \multicolumn{9}{|l|}{ Monthly income from family } \\
\hline Low & & & 1.236 & 2 & 0.539 & 1 & & \\
\hline Middle & 0.202 & 0.183 & 1.226 & 1 & 0.268 & 1.224 & 0.856 & 1.751 \\
\hline High & 0.124 & 0.204 & 0.370 & 1 & 0.543 & 1.132 & 0.759 & 1.688 \\
\hline Number of social media (1-point increase) & 0.200 & 0.038 & 28.068 & 1 & $<0.001$ & 1.221 & 1.134 & 1.315 \\
\hline 20-Item Toronto Alexithymia Scale (1-point increase) & 0.071 & 0.007 & 93.083 & 1 & $<0.001$ & 1.074 & 1.059 & 1.090 \\
\hline
\end{tabular}

$\mathrm{Cl}$, confidence interval; SE, standard error

garding the use of the content, some of their notable features may be; 1) many different types of posts such as photos, music, videos can be shared, 2) continuous and numerous sharing opportunities and fear of missing them, 3) personal followers and being followed, and 4) becoming happy when obtaining "likes." Therefore the authors think that these and similar features of social media increase the risk of control impulsivity and addiction. ${ }^{46,47}$ In addition, the present study revealed that there is no overall difference between alexithymia and social media types. As far as the authors know, this is the first such result presented in the literature. Thus, it will be useful to further investigate this issue.

According to the TAS-20 and SAS-SV scores of the 935 participants included in the study, it was revealed that $21.2 \%$ (198 students) of the participants were alexithymic and 48.7\% (455 students) of the participants had SA. These rates are not compatible with the literature because the rates of alexithymia and SA in this study are higher than most of the previous studies. ${ }^{20,26,32,48}$ One of the reasons for these high rates may be the lack of clear agreement on cut-off values in the literature. ${ }^{49}$ However, alexithymia is not a DSM diagnosis, but individuals with alexithymia have been shown to be susceptible to clinical mental disorders. For this reason, it should not be forgotten that it will be beneficial to be careful and to develop treatment protocols for mental disorders such as SA that may develop in individuals with alexithymia. ${ }^{50}$ In addition, the use of smartphones, the number of applications and the increasing Internet access to the phone can play a role here. Furthermore, it is also important to note that the concept of SA is not fully matured yet.

The study has several limitations that prevent it from in- forming future research. Firstly, all the participants were university students, therefore the results cannot be generalized to all age groups. It may be considered that the characteristics of this population, such as age, economic conditions, and working status may be a limitation for the generalization of the results. Secondly, a self-report scale was used for results. It must be kept in mind that, theoretically, these scales are always open to the practitioners being affected according to objective measurement and evaluation of the clinician. Thirdly, the cross-sectional design of the study was not sufficient to explain the causative relationship. Finally, more objective evaluations of social media use are required. Even considering these limitations, our study has important theoretical and clinical implications.

As a conclusion, the relation between alexithymia, smartphone use, and social media use was uncovered in the present study. Current findings, mainly alexithymia, contributes to the better understanding of the factors effective on SA. Being aware of the increase in the risk of SA, the results of our study suggest that it may be beneficial to consider alexithymia in therapeutic interventions in the treatment of SA. In addition, care should be taken as alexithymic individuals have a relatively high risk for SA. It will be useful for future studies to examine the causal relationship between SA and alexithymia in different segments of society with large samples.

\section{Availability of Data and Material}

The datasets generated or analyzed during the study are available from the corresponding author on reasonable request.

\section{Conflicts of Interest}

The authors have no potential conflicts of interest to disclose. 


\section{Author Contributions}

Conceptualization: İbrahim Gündoğmuş, Ayhan Algül. Data curation: all authors. Formal analysis: İbrahim Gündoğmuş. Funding acquisition: İbrahim Gündoğmuş, Mehmet Sinan Aydın. Investigation: İbrahim Gündoğmuş, Mehmet Sinan Aydın. Methodology: İbrahim Gündoğmuş, Ayhan Algül. Project administration: İbrahim Gündoğmuş. Resources: Mehmet Sinan Aydın. Software: Ayhan Algül. Supervision: all authors. Validation: all authors. Visualization: İbrahim Gündoğmuş. Writingoriginal draft: İbrahim Gündoğmuş. Writing_-review \& editing: all authors.

\section{ORCID iDs}

İbrahim Gündoğmuş Mehmet Sinan Aydın Ayhan Algül

https://orcid.org/0000-0002-1921-1495 https://orcid.org/0000-0002-7218-3972 https://orcid.org/0000-0002-6570-7141

\section{Funding Statement}

None.

\section{REFERENCES}

1. Ishii K. Examining the adverse effects of mobile phone use among Japanese adolescents. Keio Comm Rev 2011;33:69-83.

2. Kwon M, Lee JY, Won WY, Park JW, Min JA, Hahn C, et al. Development and validation of a smartphone addiction scale (SAS). PLoS One 2013;8:e56936.

3. American Psychiatric Association. Diagnostic and Statistical Manual of Mental Disorders (DSM- $5^{\circledR}$ ). Washington DC: American Psychiatric Pub; 2013.

4. Aljomaa SS, Qudah MFA, Albursan IS, Bakhiet SF, Abduljabbar AS. Smartphone addiction among university students in the light of some variables. Comput Human Behav 2016;61:155-164.

5. Haug S, Castro RP, Kwon M, Filler A, Kowatsch T, Schaub MP. Smartphone use and smartphone addiction among young people in Switzerland. J Behav Addict 2015;4:299-307.

6. Griffiths M. Gambling on the internet: a brief note. J Gambl Stud 1996; 12:471-473.

7. Coban DA, Gundogmus I. Effect of smartphone usage profiles on addiction in a university student: a cross-sectional study. Dusunen Adam J Psychiatr Neurol Sci 2019;32:87.

8. Al-Khlaiwi T, Meo SA. Association of mobile phone radiation with fatigue, headache, dizziness, tension and sleep disturbance in Saudi population. Saudi Med J 2004;25:732-736.

9. Khan MM. Adverse effects of excessive mobile phone use. Int J Occup Med Environ Health 2008;21:289-293.

10. Bert F, Giacometti M, Gualano MR, Siliquini R. Smartphones and health promotion: a review of the evidence. J Med Syst 2014;38:9995.

11. Kuss DJ, Griffiths MD. Online social networking and addiction--a review of the psychological literature. Int J Environ Res Public Health 2011;8:3528-3552.

12. Repacholi MH. Health risks from the use of mobile phones. Toxicol Lett 2001;120:323-331.

13. Thomée S, Härenstam A, Hagberg M. Mobile phone use and stress, sleep disturbances, and symptoms of depression among young adultsa prospective cohort study. BMC Public Health 2011;11:66.

14. Gundogmus I, Kul AT, Coban DA. Investigation of the relationship between social network usage and sleep quality among university students/ Universite ogrencilerinde sosyal ag kullanimi ve uyku kalitesi arasindaki iliskisinin arastirilmasi. Anadolu Psikiyatri Dergisi 2020: 141-149.

15. Gao T, Li J, Zhang H, Gao J, Kong Y, Hu Y, et al. The influence of alexithymia on mobile phone addiction: the role of depression, anxiety and stress. J Affect Disord 2018;225:761-766.

16. Taylor GJ, Bagby RM, Parker JD. Disorders of Affect Regulation: Alexithymia in Medical and Psychiatric Illness. Cambridge: Cambridge Uni- versity Press; 1999.

17. Lumley MA, Roby KJ. Alexithymia and pathological gambling. Psychother Psychosom 1995;63:201-206.

18. Kun B, Demetrovics Z. [The role of emotional intelligence in addiction disorders]. Psychiatr Hung 2010;25:503-524.

19. Morie KP, Yip SW, Nich C, Hunkele K, Carroll KM, Potenza MN. Alexithymia and addiction: a review and preliminary data suggesting neurobiological links to reward/loss processing. Curr Addict Rep 2016; 3:239-248.

20. Scimeca G, Bruno A, Cava L, Pandolfo G, Muscatello MRA, Zoccali R. The relationship between alexithymia, anxiety, depression, and internet addiction severity in a sample of Italian high school students. ScientificWorldJournal 2014;2014:504376.

21. Montag C, Błaszkiewicz K, Sariyska R, Lachmann B, Andone I, Trendafilov B, et al. Smartphone usage in the 21st century: who is active on WhatsApp? BMC Res Notes 2015;8:331.

22. Mei S, Xu G, Gao T, Ren H, Li J. The relationship between college students' alexithymia and mobile phone addiction: testing mediation and moderation effects. BMC Psychiatry 2018;18:329.

23. Hao Z, Jin L, Li Y, Akram HR, Saeed MF, Ma J, et al. Alexithymia and mobile phone addiction in Chinese undergraduate students: the roles of mobile phone use patterns. Comput Human Behav 2019;97:51-59.

24. Elkholy H, Elhabiby M, Ibrahim I. Rates of alexithymia and its association with smartphone addiction among a sample of university students in Egypt. Front Psychiatry 2020;11:304.

25. Mattila AK, Luutonen S, Ylinen M, Salokangas RK, Joukamaa M. Alexithymia, human relationships, and mobile phone use. J Nerv Ment Dis 2010;198:722-727.

26. Dalbudak E, Evren C, Aldemir S, Coskun KS, Ugurlu H, Yildirim FG. Relationship of internet addiction severity with depression, anxiety, and alexithymia, temperament and character in university students. Cyberpsychol Behav Soc Netw 2013;16:272-278.

27. Yates TM, Gregor MA, Haviland MG. Child maltreatment, alexithymia, and problematic internet use in young adulthood. Cyberpsychol Behav Soc Netw 2012;15:219-225.

28. Kardefelt-Winther D. The moderating role of psychosocial well-being on the relationship between escapism and excessive online gaming. Comput Human Behav 2014;38:68-74.

29. Kardefelt-Winther D. A conceptual and methodological critique of internet addiction research: towards a model of compensatory internet use. Comput Human Behav 2014;31:351-354.

30. Gao W, Chen Z. A study on psychopathology and psychotherapy of Internet addiction. Adv Psychol Sci 2006;14:596-603.

31. Noyan C, Enez Darçın A, Nurmedov S. Validity and reliability of the Turkish version of the Smartphone Addiction Scale-Short Version among university students. Anat J Psychiatry 2015;16:73-81.

32. Kwon M, Kim DJ, Cho H, Yang S. The smartphone addiction scale: development and validation of a short version for adolescents. PLoS One 2014;8:e83558.

33. Güleç H, Köse S, Güleç MY, Çitak S, Evren C, Borckardt J, et al. Reliability and factorial validity of the Turkish version of the 20 -item Toronto alexithymia scale (TAS-20). Bull Clin Psychopharmacol 2009;19: 214-220.

34. Bagby RM, Parker JD, Taylor GJ. The twenty-item Toronto Alexithymia Scale--I. Item selection and cross-validation of the factor structure. J Psychosom Res 1994;38:23-32.

35. Güleç H, Yenel A. Psychometric properties of the Turkish version 20 Item Toronto Alexithymia Scala: according to cut-off score. Turk J Clin Psychiatry 2010;13:108-112.

36. Budak E, Taymur I, Askin R, Gungor BB, Demirci H, Akgul AI, et al. Relationship between internet addiction, psychopathology and self-esteem among university students. Eur Res J 2015;1:128-135.

37. Heaven PC, Ciarrochi J, Hurrell K. The distinctiveness and utility of a brief measure of alexithymia for adolescents. Pers Individ Diff 2010; 49:222-227. 
38. Griffiths M. Does internet and computer" addiction" exist? Some case study evidence. CyberPsychol Behav 2000;3:211-218.

39. Caplan SE. A social skill account of problematic internet use. J Comm 2005;55:721-736.

40. Choi SW, Kim DJ, Choi JS, Ahn H, Choi EJ, Song WY, et al. Comparison of risk and protective factors associated with smartphone addiction and Internet addiction. J Behav Addict 2015;4:308-314.

41. Çağan Ö, Ünsal A, Çelik N. Evaluation of college students' the level of addiction to cellular phone and investigation on the relationsship between the addiction and the level of depression. Proc Soc Behav Sci 2014;114:831-839.

42. Jeong SH, Kim H, Yum JY, Hwang Y. What type of content are smartphone users addicted to?: SNS vs. games. Comput Human Behav 2016; 54:10-17.

43. Milošević-Đorđević JS, Žeželj IL. Psychological predictors of addictive social networking sites use: The case of Serbia. Comput Human Behav 2014;32:229-234.

44. Salehan M, Negahban A. Social networking on smartphones: when mo- bile phones become addictive. Comput Human Behav 2013;29:26322639.

45. Emre Ç, Isbulan O. A new addiction for teacher candidates: social networks. Turk Online J Educ Technol 2012;11.

46. Kuss DJ, Griffiths MD. Online social networking and addiction-a review of the psychological literature. Int J Environ Res Public Health 2011;8:3528-3552.

47. Cabral J. Is generation Y addicted to social media. Fut Child 2008;18: 125.

48. Baysan-Arslan S, Cebeci S, Kaya M, Canbal M. Relationship between internet addiction and alexithymia among university students. Clin Investig Med 2016;39:111-115.

49. Loas G, Fremaux D, Otmani O, Verrier A. [Prevalence of alexithymia in a general population. Study in 183 "normal" subjects and in 263 students]. Ann Med Psychol (Paris) 1995;153:355-357.

50. Leweke F, Leichsenring F, Kruse J, Hermes S. Is alexithymia associated with specific mental disorders. Psychopathology 2012;45:22-28. 